\title{
HUBUNGAN TINGKAT PENGETAHUAN DENGAN PERILAKU CUCI TANGAN MENGGUNAKAN HANDRUB PADA KELUARGA PASIEN DI RUANG BEDAH RSUD DR. H. MOH. ANWAR SUMENEP
}

\author{
Elyk Dwi Mumpuningtias, Sugesti Aliftitah, Illiyini
}

\section{elykfik@wiraraja.ac.id}

\begin{abstract}
Program Studi Ilmu Keperawatan Fakultas Ilmu Kesehatan Universitas Wiraraja
\end{abstract}
\begin{abstract}
Hand hygiene is a core element for protecting patients against nosocomial infection. Hand hygiene by alcohol-based hand rub is a simple and quick procedure that takes only a few seconds. The problem in this research is there were so many patient's families who had not been using handrub liquid although the hospital already provide it, especially in Bedah Room RSUD dr. H. Moh. Anwar Sumenep. The aim of this research is to analyze the correlation between knowledge level with hand hygiene behavior using handrub on patient's family in Bedah Room RSUD dr. H. Moh. Anwar Sumenep. The design of this study was analytic with cross sectional design. The population in this research was the entire patient's family in Bedah Room RSUD dr. H. Moh. Anwar Sumenep. The number of samples was 60 people of patient's family and sample was selected by Purposive Sampling technique. The independent variable is knowledge level and the dependent variable is hand hygiene behavior using handrub on patient's family. The data collected by using questionnaires and observation sheets. The research result shows that mostly of patient's family has deficient knowledge level, that was 44 people $(73,3 \%)$ and almost all of respondents did not do hand hygiene using handrub, that was 49 people $(81,7 \%)$. The result of statistic test by Fisher's Exact test is obtained $P$ value $<\alpha(0.000<0.05)$. So, there is a correlation between knowledge level with hand hygiene behavior using handrub on patient's family in Surgery Room RSUD dr. H. Moh. Anwar Sumenep. Therefore, the level of knowledge can affect hand hygiene behavior using handrub to avoid disease threat and nosocomial infection, good knowledge level is needed.
\end{abstract}

Keywords: Knowledge, Hand Hygiene Behavior, Handrub.

\section{PENDAHULUAN}

WHO mencetuskan global patient safety challenge dengan clean is safer care, yaitu pada pemberian pelayanan atau perawatan secara bersih untuk mewujudkan keselamatan pasien (patient safety) pada tahun 2009. Salah satunya yaitu dengan cara merumuskan inovasi strategi penerapan hand hygiene untuk petugas kesehatan dengan my five moments for hand hygiene (WHO dalam Sudrajat, 2015).

Petugas medis sudah menerapkan hand hygiene, namun ada kalanya pihak keluarga pasien tidak ikut menerapkannya walaupun di rumah sakit telah tersedia wastafel dan handrub di setiap ruangan rawat inap. Hal ini tentu dapat menjadi faktor penyebab tidak tercapainya hak pasien dalam UU Nomor 44 tahun 2009 tersebut. Presentase infeksi nosokomial di rumah sakit dunia mencapai angka 9\% (variasi 3-21\%) atau lebih 1,4 juta pasien rawat inap mendapatkan infeksinosokomial (WHO dalam Fauzia \& Ahsan, 2014). Di negara berkembang termasuk Indonesia, rata-rata prevalensi infeksi nosokomial adalah sekitar $9,1 \%$ dengan variasi $6,1 \%-$ 
16,0\% (Hasbullah dalam Fauzia \& Ahsan, 2014).

Dari hasil survey yang dilakukan di ruang rawat inap RSUD dr. $\mathrm{H}$. Moh. Anwar ditemukan bahwa hanya 2 dari 10 keluarga pasien yang menerapkan hand hygiene dengan penggunaan handrub saat sebelum dan sesudah berinteraksi dengan pasien.

Cara paling efektif untuk mencegah terjadinya infeksi nosokomial adalah dengan menjalankan universal precautian yang salah satunya adalah dengan melakukan hand hygiene pada setiap penangprataanan pasien di rumah sakit. Hand hygiene menjadi salah satu langkah yang efektif untuk memutuskan rantai transmisi infeksi, sehingga insidensi nosokomial dapat berkurang. Pencegahan dan pengendalian infeksi mutlak harus dilakukan oleh perawat, dokter dan seluruh orang yang terlibat dalam perawatan pasien (Duerink dalam Fauzia \& Ahsan, 2014).

Karena seluruh orang yang terlibat dalam perawatan pasien juga termasuk salah satu komponen untuk pencegahan dan pengendalian infeksi, maka penulis tertarik untuk meneliti tentang hubungan tingkat pengetahuan keluarga pasien dengan perilaku cuci tangan menggunakan handrub di Ruang Bedah RSUD dr. $\mathrm{H}$. Moh. Anwar Sumenep.

\section{Metode Penelitian}

Metode yang digunakan adalah observasional analitik dengan pendekatan cross sectionaldimana penelitian ini menekankan waktu pengukuran/observasi data variabel independen dan dependen hanya satu kali, pada jenis ini variable independendan dependen dinilai secara simultan pada saat itu, jadi tidak ada tindak lanjut (Nursalam, 2016).

Populasi dalam penelitian ini semua keluarga pasien rawat inap di Ruang Bedah RSUD. dr. H. Moh. Anwar Sumenep.Teknik pengambilan sampel yang digunakan dalam penelitian ini adalah metode teknik purposive sampling. Sampel dalam penelitian ini adalah salah satu dari keluarga inti (ayah/ibu/anak) pasien yang secara teratur menunggui pasien setiap harinya, dalam penelitian ini jumlah sampel sebanyak 60 responden.

Pengumpulan data dalam penelitian menggunakan instrumen kuesioner dan lembar observasi. Peneliti mengobservasi apakah responden melakukan cuci tangan menggunakan handrub sebelum dan setelah kontak dengan pasien.Analisis data penelitian ini dengan uji non parametrikUji Fisher menggunakan softwareSPSS.

\section{Hasil Penelitian}

1. Data Tingkat Pengetahuan Keluarga Pasien di Ruang Bedah RSUD dr. H. Moh. Anwar Sumenep Mei 2017

Tabel 1 Distribusi frekuensi keluarga pasien berdasarkan tingkat pengetahuan tentang handrub di Ruang Bedah RSUD dr. H. Moh. Anwar Sumenep, Mei 2017

\begin{tabular}{ccc}
\hline Pengetahuan Keluarga Pasien & Frekuensi (n) & Persentase (\%) \\
\hline Baik & 6 & $10 \%$ \\
Cukup & 10 & $16,7 \%$ \\
Kurang & 44 & $60 \%$ \\
\hline Jumlah & $\mathbf{6 0}$ & $\mathbf{1 0 0 \%}$ \\
\hline
\end{tabular}

Berdasarkan tabel 5.5 didapatkan bahwa sebagian besar tingkat pengetahuan keluarga pasien adalah berkarakteristik kurang yaitu sebanyak 44 orang $(73,3 \%)$.

2. Data Perilaku Cuci Tangan Menggunakan Handrub pada Keluarga Pasien di Ruang Bedah RSUD dr. H. Moh. Anwar Sumenep Tahun 2017 
Tabel 2 Distribusi frekuensi Perilaku Cuci Tangan Menggunakan Handrub pada Keluarga Pasien di Ruang Bedah RSUD dr. H. Moh. Anwar Sumenep, Mei 2017

\begin{tabular}{ccc}
\hline $\begin{array}{c}\text { Perilaku Cuci Tangan Menggunakan } \\
\text { Handrub }\end{array}$ & Frekuensi (n) & Persentase (\%) \\
\hline Melakukan & 11 & $18,3 \%$ \\
Tidak Melakukan & 49 & $81,7 \%$ \\
\hline Jumlah & $\mathbf{6 0}$ & $\mathbf{1 0 0 \%}$ \\
\hline
\end{tabular}

Berdasarkan tabel 5.6 menunjukkan bahwa hampir seluruh keluarga pasien tidak melakukan cuci tangan menggunakan handrub, yaitu sebanyak 49 orang $(81,7 \%)$.

\section{Hubungan Tingkat Pengetahuan dengan Perilaku Cuci Tangan Menggunakan Handrub}

Tabel 3 Tabulasi silang hubungan tingkat pengetahuan dengan perilaku cuci tangan menggunakan handrub pada keluarga pasien di Ruang Bedah RSUD dr. H. Moh. Anwar Sumenep.

\begin{tabular}{|c|c|c|c|c|c|c|}
\hline \multirow{3}{*}{$\begin{array}{c}\text { Tingkat } \\
\text { Pengetahuan }\end{array}$} & \multicolumn{4}{|c|}{$\begin{array}{c}\text { Perilaku Cuci Tangan } \\
\text { Menggunakan Handrub }\end{array}$} & \multirow{3}{*}{ Frekuensi (n) } & \multirow{3}{*}{ Persentase $(\%)$} \\
\hline & \multicolumn{2}{|c|}{ Melakukan } & \multicolumn{2}{|c|}{$\begin{array}{c}\text { Tidak } \\
\text { Melakukan }\end{array}$} & & \\
\hline & $\mathbf{f}$ & $\%$ & f & $\%$ & & \\
\hline Baik & 6 & 100 & 0 & 0 & 6 & $100 \%$ \\
\hline Cukup & 4 & 40 & 6 & 60 & 10 & $100 \%$ \\
\hline Kurang & 1 & 2,3 & 43 & 97,7 & 44 & $100 \%$ \\
\hline Total & 11 & 18,3 & 49 & 81,7 & 60 & $100 \%$ \\
\hline
\end{tabular}

Fisher's ExactTest

Exact Sig $=0,00>\alpha=0,05$

Hasil uji Fisher menujukkan signifkasi uji (Exact Sig) 0,00 $(\alpha=0,05)$. Dengan $p$ value lebih kecil dari $\alpha$ maka $\mathrm{H} 1$ diterima dan Ho ditolak yang berarti ada hubungan antara tingkat pengetahuan dengan perilaku cuci tangan menggunakan handrub pada keluarga pasien.

\section{PEMBAHASAN}

1. Tingkat Pengetahuan Keluarga Pasien di Ruang Bedah RSUD dr. H. Moh. Anwar Sumenep tentang Perilaku Cuci Tangan Menggunakan Handrub.

Pengetahuan sebagian besar masyarakat tentang cuci tangan masih kurang, khususnya cuci tangan menggunakan handrub. Handrub merupakan benda yang sudah tidak asing di kalangan masyarakat luas dan sudah dijual bebas, hanya saja penggunaannya kurang maksimal. Padahal di rumah sakit, handrub merupakan salah satu komponen penting untuk mencegah terjadinya infeksi nosokomial yang mengancam semua warga rumah sakit. Tingkat pengetahuan masyarakat yang kurang ini dapat diatasi salah satunya dengan cara adanya promosi kesehatan, seperti pemasangan handrub di dindingdinding rumah sakit lengkap dengan penjelasan singkat serta langkah-langkah yang benar. Dengan begitu, masyarakat diharapkan mulai mengenal handrub dan bahkan sampai mengimplementasikannya selama di rumah sakit.

2. Perilaku Cuci Tangan Menggunakan Handrub pada Keluarga Pasien di Ruang Bedah RSUD dr. H. Moh. Anwar Sumenep. 
Berdasarkan hasil penelitian menunjukkan bahwa hampir seluruh keluarga pasien di Ruang Bedah RSUD dr. H. Moh. Anwar Sumenep tidak melakukan handrubing.Kebersihan tangan adalah elemen inti untuk melindungi pasien terhadap HAIs. Mencuci tangan dengan cara menggosok tangan menggunakan alkohol (alcohol-based) adalah prosedur yang sederhana dan ringan yang membutuhkan hanya beberapa detik saja (Sax H, et al. dalam Rikayanti \& Arta, 2014). Perilaku ditentukan atau terbentuk dari beberapa faktor, yaitu pengetahuan, sikap, afeksi dan kognisi. Afeksi merupakan komponen emosional dan perasaan (Notoatmodjo, 2010).

Promosi kesehatan merupakan langkah yang bisa dilakukan dalam upaya meningkatkan tingkat pengetahuan masyarakat di rumah sakit tentang handrub. Upaya yang dapat dilakukan misalnya dengan pemasangan poster atau banner yang bersifat mengajak untuk cuci tangan mengunakan handrub, berikut juga langkah-langkah yang benar saat menggunakan handrub. Semua itu diringkas dengan tampilan yang jelas dan menarik perhatian sehinggamasyarakat mulai mengenali keberadaan handrub dan diharapkan dapat mengaplikasikannya sesuai dengan fungsi, cara dan waktu yang benar.

3. Hubungan Tingkat Pengetahuan dengan Perilaku Cuci Tangan Menggunakan Handrub pada Keluarga Pasien di Ruang Bedah RSUD dr. H. Moh. Anwar Sumenep Tahun 2017.

Menilik dari perilaku sebagian besar keluarga pasien di Ruang Bedah RSUD dr. H. Moh. Anwar Sumenep, dapat terlihat rata-rata tingkat pengetahuan responden tentang perilaku cuci tangan menggunakan handrub masih kurang. Padahal rumah sakit telah menyediakan sarana dan prasarana berupa handrub, lengkap dengan keterangan serta gambar dari langkahlangkah mencuci tangan menggunakan handrub. Ditambah lagi terdapatbeberapa poster tentang cuci tangan menggunakan handrub di sudut-sudut beberapa ruangan.

Kurangnya pengetahuan keluarga pasien tentang handrub tampaknya juga disebabkab karena letak handrub yang mudah terlewatkan dari pandangan mata dan pamflet tentang langkah-langkah cuci tangan menggunakan handrub yang agak kecil sehingga sering luput dari perhatian. Selain itu kurangnya komunikasi antara petugas kesehatan dan keluarga pasien juga menjadi salah satu faktor kurangnya pengetahuan, sehingga terjadi kesalahpahaman seperti anggapan bahwa handrub hanya boleh digunakan oleh petugas rumah sakit saja.

\section{KESIMPULAN}

1. Sebagian besar tingkat pengetahuan keluarga pasien tentang handrub di Ruang Bedah RSUD dr. H. Moh. Anwar Sumenep dalam kategori tingkat pengetahuan kurang.

2. Hampir seluruh keluarga pasien di Ruang Bedah RSUD dr. H. Moh. Anwar Sumenep tidak mencuci tangan menggunakan handrub.

3. Ada hubungan antara tingkat pengetahuan dengan perilaku cuci tangan menggunakan handrub pada keluarga pasien di Ruang Bedah RSUD dr. H. Moh. Anwar Sumenep.

\section{REFERENSI}

Arifianto. 2017. Kepatuhan Perawat dalam Menerapkan Sasaran Keselamatan Pasien pada Pengurangan Resiko Infeksi dengan Penggunaan Alat Pelindung Diri di Rs. Roemani Muhammadiyah Semarang. Tesis. Fakultas Kedokteran Universitas Diponegoro Semarang.

Arikunto. 2006. Prosedur Penelitian Suatu Pendekatan Praktek. Jakarta: RinekaCipta.

Ernawati, Elies. 2014. Penerapan Hand Hygiene Perawat di Ruang Rawat Inap Rumah Sakit. Jurnal 
Kedokteran Brawijaya, Vol. 28. Rumah Sakit Islam Hasanah Muhammadiyah, Mojokerto.

Fauzia, Neila., Ahsan. 2014. Pengaruh Faktor Individu, Organisasi dan Perilaku terhadap Kepatuhan Perawat dalam Melaksanakan Hand Hygiene di Ruang Rawat Inap Rumah Sakit Tk. II Dr. Soepraoen Malang. Fakultas Kedokteran Universitas Brawijaya Malang.

Firdausy, Dea., Emmy., Husodo. (2016). Faktor-Faktor yang Berhubungan dengan Perilaku Penggunaan Antiseptic Handrub pada Penunggu Pasien Rawat Inap di Bangsal Dahlia Kelas III RSUD Kabupaten Brebes. Jurnal Kesehatan Masyarakat, Vol. 4, Nomor 5, Oktober 2016.

Hidayat, Azis, A. 2007. Metode Penelitian Keperawatan dan Teknik Analisis.Jakarta: Salemba Medika.

Handiyani, Hanny., Fauzia, Sarah. 2014.

Tingkat Pengetahuan dan

Perilaku Kebersihan Tangan pada

Pengunjung Rumah Sakit.

Fakultas Ilmu Keperawatan, Universitas Indonesia.

Indarti, Wilis. 2014. Hubungan Pengalaman Kerja Perawat dengan KepatuhanCuci Tangan di RSU PKU Muhammadiyah Bantul. Sekolah Tinggi IlmuKesehatan 'Aisyiyah Yogyakarta

Khoiruddin, Kimantoro, Sutanta. 2015. Tingkat Pengetahuan Berhubungan dengan Sikap Cuci Tangan Bersih Pakai Sabun Sebelum dan Setelah Makan pada Siswa SDN Ngebel Tamantirta, Kasihan, Bantul. Jurnal Ners dan Kebidanan, Program Studi Ners Sekolah Tinggi Ilmu Kesehatan. Yogyakarta.

Meida, Enung Ayu. 2016. Pengaruh Pendidikan Kesehatan. Fakultas IlmuKesehatan UMP
Notoatmodjo 2003. Pengantar Pendidikan Kesehatan dan Ilmu Perilaku. Jakarta: Andi Offset.

Notoatmodjo, $\quad$ Soekidjo. 2010. Pendidikan dan Perilaku Kesehatan. Jakarta: Rineka Cipta. Notoatmodjo, Soedikjo. 2005. Meteodologi Penelitian Kesehatan. Jakarta: RinekaCipta.

Notoatmodjo, Soekidjo. 2007. Promosi Kesehatan dan Ilmu Perilaku. Jakarta: Rineka Cipta.

Nursalam. 2016. Konsep dan Penerapan Metodologi Penelitian Ilmu Keperawatan, Pedoman Skripsi, Tesis, dan Instrumen Penelitian Keperawatan. Jakarta: Salemba Medika.

Pratama,dkk. 2015. Faktor Determinan Kepatuhan Pelaksanaan Hand Hygiene pada Perawat IGD RSUD dr. Iskak Tulungagung. Jurnal Kedokteran Brawijaya, Vol. 28. Magister Manajemen Rumah Sakit Fakultas Kedokteran Universitas Brawijaya Malang.

Prihatin, Lhelyana. 2015. Tingkat Pengetahuan Siswa Tentang Cuci Tangan Pakai Sabun di SMP N 2 Mojolaban Sukoharjo. Karya Tulis Ilmiah. Sekolah Tinggi Ilmu Kesehatan Kusuma Husada Surakarta.

Rikayanti, Kadek Herna., Arta, Sang Ketut. 2014. Hubungan Tingkat Pengetahuan dengan Perilaku Mencuci Tangan Petugas Kesehatan di Rumah Sakit Umum Daerah Badung Tahun 2013. Artikel Penelitian. Ilmu Kesehatan Masyarakat Fakultas Kedokteran Universitas Udayana.

Soedarmo, Sumarno S, dkk, 2008, Buku Ajar Infeksi dan Pediatri Tropis EdisiKedua, Jakarta: Ikatan Dokter Anak Indonesia.

Sudrajat, Fedi. 2015. Faktor-Faktor yang Berhubungan dengan Kepatuhan Perawat dalam Pelaksanaan 
Hand Hygiene Sebelum Tindakan Keperawatan. Skripsi. Sekolah Tinggi Ilmu Kesehatan Muhammadiyah Gombong.

Walgito, Bimo, 2003. Pengantar Psikologi Umum. Andi: Yogyakarta.

Wawan, A., M, Dewi. 2011. Teori \& Pengukuran Pengetahuan, Sikap, dan Perilaku Manusia Dilengkapi Contoh Kuesioner. Nuha Medika: Yogyakarta.

Widiawati, Eka. 2015. Efektivitas Pemberian Pendidikan Kesehatan Cuci Tangan pada Pengunjung di Bangsal Ar-Royan $R \quad R S P K U$ Muhammadiyah Yogyakarta Unit II. Skripsi. Fakultas Kedokteran dan Ilmu Kesehatan. Universitas Muhammadiyah Yogyakarta 